\section{El quehacer teológico y el método de investigación acción participativa} Una reflexión metodológica*

\section{Olga Consuelo Vélez Caro**}

RECIBIDO: 10-06-16. APROBADO: 02-09-16

Resumen: El artículo pretende examinar las articulaciones entre los métodos en teología y el método de las ciencias sociales investigación acción participativa (IAP) teniendo en cuenta la importancia que este último tiene para la elaboración de las teologías contextuales. Se examinan brevemente los métodos en teología y se presenta el método de investigación acción participativa. Con tal contextualización se pueden advertir las posibilidades y límites que esta articulación metodológica ofrece y se invita a continuar este caminar teológico que toma en serio la autonomía de la realidad y pretende descubrir en ella la revelación de Dios que la ilumina y, efectivamente, la transforma.

Palabras Clave: Método, epistemología, liberación, teología de la acción, investigación-acciónparticipativa.
Theological Work and the Participatory Action Research Method. A Theological Reflection

Aвstract: The article intends to examine the articulations between the methods in Theology and the Social Sciences method of Participatory Action Research (PAR), taking into account the importance that the latter has for the development of contextual theologies. Methods in Theology are briefly examined and the Participatory Action Research's method is presented. Such contextualization shows the possibilities and limits of this methodological articulation. Besides, it invites us to continue the theological journey that takes seriously into account the autonomy of reality and seeks to discover God's revelation in reality, which enlightens and effectively transforms it.

Key Words: Method, Epistemology, Liberation, Theology of Action, Participatory Action Research.

\section{PARA CITAR ESTE ARTÍ́CULO:}

Vélez Caro, Olga Consuelo. "El quehacer teológico y el método de investigación acción participativa. Una reflexión metodológica”. Theologica Xaveriana 183 (2017): 187-208. https://doi.org/10.11144/javeriana.tx67-183.qtmiap

\footnotetext{
* Este es uno de los productos de la investigación "Experiencia de Dios en la corporeidad y la sexualidad de un grupo de pacientes de la Unidad de Infectología del Hospital Universitario San Ignacio", en lo que se refiere a la fundamentación metodológica desde la teología, financiada por la Iglesia Sueca y la Pontificia Universidad Javeriana (ID propuesta 00006387).

** Doctora en Teología. Profesora titular e investigadora de la Facultad de Teología de la Pontificia Universidad Javeriana. Coordinadora del grupo de investigación “Teología y mundo contemporáneo". OrCiD: 0000-0002-4663-8005. Correo electrónico: ocvelez@javeriana.edu.co
} 


\section{Introducción}

La teología entendida como una "mediación entre una determinada matriz cultural y el significado y función de una religión dentro de dicha matriz" ${ }^{1}$ nos sitúa en la necesidad de reflexionar sobre su método. La razón de esta afirmación radica en que si la teología concibe la cultura en su acepción clásica ${ }^{2}$ no hay mucha necesidad de pensar en el método porque su objeto es reflexionar sobre su naturaleza, ya que se considera una realización acabada que se transmite de generación en generación y se repite tal y como está formulada; pero cuando se concibe como mediación entre cultura y religión (y por cultura entiende "el conjunto de significados y valores que informan un determinado modo de vida”, y por religión, el pluralismo religioso), la teología es un proceso evolutivo, siempre en movimiento, y la garantía de su rigurosidad y fundamentación radica en su método.

De ahí la pertinencia de esa reflexión: ¿Cómo hacer hoy teología? Esta pregunta se ha hecho desde los inicios del quehacer teológico pero -como acabamos de decirla manera de concebirla determina la centralidad o no del método. Una descripción de los métodos empleados a lo largo de la historia nos permite tomar contacto con la tarea metódica y situar la reflexión que pretendemos hacer aquí. Nos referiremos a la patrística, la escolástica, la teología moderna y, desde el contexto latinoamericano, la teología de la liberación y las demás teologías contextuales 3 .

En la patrística, el método podemos llamarlo "sapiencial". Los padres de la Iglesia conciben la teología como un cogito fidei, es decir, saborear los misterios de la fe. La sapientia o -si queremos- la gnosis como comprensión globalizante, sabrosa, íntima e intuitiva de la fe es el modelo de razón de los padres. Se trata de una contemplación intelectual en la que se implica el teólogo para comunicar su propia experiencia de fe a los destinatarios. En ese tiempo también se da una reflexión sistemática usando las categorías griegas y construyendo los primeros tratados teológicos; esto último, a

\footnotetext{
${ }^{1}$ Lonergan, Método en teología, 9.

${ }^{2}$ Por cultura clásica Lonergan entiende una sola cultura, universal y permanente. Sus normas e ideales podían ser objeto de las aspiraciones de las personas no-cultas. Por cultura empírica se refiere al conjunto de significaciones y valores que informan un determinado modo de vida. Puede permanecer inmutable durante siglos, pero puede también estar sometido a un proceso de lento desarrollo o de rápida desintegración (Lonergan, Método en teología, 9). No se está desconociendo que la teología, en su larga historia, haya tenido un método o métodos y que se ha desarrollado gracias a ellos. En lo que Lonergan enfatiza es en el cambio de paradigma que surge cuando se concibe la cultura no de manera "clásica", una "única" cultura y, por supuesto "occidental", sino de manera "empírica": pluralidad de culturas.

${ }^{3}$ Seguimos fundamentalmente los aportes de Boff, Teoria do método teológico, 138-153. También puede verse un cuadro síntesis de algunas de estas teologías contextuales en Vélez, El método teológico. Fundamentos, especializaciones, enfoques, 293-295.
} 
partir de una necesidad particular: responder a las herejías y afirmar la fe u ortodoxia y, de ahí, su carácter apologético. De esta manera de teologizar son fruto los concilios trinitarios y cristológicos de esos siglos. Las mediaciones de este tipo de teología son la filosofía griega de corte platónico, estoico, y algunas influencias del aristotelismo.

En la escolástica (siglo XIII), la teología entra a la universidad y se hace disciplina académica al lado de otras: las artes (filosofía), la medicina y el derecho. Hay que anotar que la teología se considera en este momento como la "reina" de todas las disciplinas. Es una teología racional que aspira a dar razones de los artículos de fe y pretende construirse como toda ciencia. Parte de las quaestiones para iluminarlas con las lectiones -basadas en la Sagrada Escritura y las categorías filosóficas griegas- y se prolongan en las disputationes.

Su objetivo es presentar un sistema completo de toda la reflexión teológica y sus resultados se presentan en las sumas teológicas. Las mediaciones de este tipo de teología son la dialéctica, entendida como el uso metódico de la razón que -en ese tiempo- está marcado por el aristotelismo, tanto en sus tratados lógicos como en sus contenidos: metafísica, ética, política y cosmología.

La teología moderna pretende resolver los desafíos de la Modernidad. La independencia de la razón de los fundamentos filosóficos para apoyarse en la ciencia y el progreso llevan a privilegiar la reflexión, la crítica y la autocrítica. Sin embargo, su mayor tentación ha sido quedar presa de las demostraciones y de la razón eficiente, y ahogar el misterio de la fe que siempre ha de mantener la primacía.

No obstante, su desarrollo y consolidación ha supuesto un avance inmenso para la teología, y en la actualidad es preciso hablar de "teologías" en plural porque sus discursos o ensayos -como algunos prefieren llamarlos- no se ocupan tanto del polo ontológico u objetivo de la fe, sino del polo subjetivo o antropológico, con todo lo que supone de personal, inmanente, vivencial, experiencial, práctico.

Dos niveles han marcado este desarrollo teológico: el nivel personal y el nivel social. En el primero se sitúan más las teologías de corte existencial y en el segundo las de corte político. De estas últimas se desprenden las llamadas teologías de la liberación de los terceros mundos. Las mediaciones de estas teologías son de corte antropológico -como ya hemos seńalado-, de corte secular por el reconocimiento de la "autonomía de las realidades terrestres", de corte histórico, social, político y hermenéutico (cuestiones del lenguaje y de la interpretación).

Las teologías de la liberación, con sus desdoblamientos de sujetos, etnias, ecológicos, pluralismos culturales y religiosos, etc., se caracterizan por su intencionalidad práctica, tanto en su punto de partida -la experiencia de subordinación o pobreza o discriminación o atropello, etc.- como en su objetivo final: la transformación de 
las realidades consideradas. Sus mediaciones son especialmente las ciencias sociales y humanas y asumen el círculo hermenéutico que permite tomar las preguntas que surgen del "contexto" (praxis histórica), para iluminarlo con "textos revelados" (a la luz de la fe), desde los pretextos o intencionalidades (reflexión crítica) marcados por la liberación y la búsqueda de transformación de la realidad ${ }^{4}$.

Precisamente en este horizonte de mediaciones nos preguntamos por la articulación del método de investigación acción participativa con los métodos en teología, especialmente los de las teologías contextuales ${ }^{5}$, tan presentes en nuestro quehacer teológico latinoamericano.

El método de investigación acción participativa, propio de las ciencias sociales, tiene una larga trayectoria en el continente latinoamericano y en otras realidades, y pretende no solo producir conocimiento sino también transformar la realidad investigada. En el conocimiento teológico, los métodos de las ciencias sociales han prestado a las teologías contextuales, por ejemplo, la teología de la liberación, un servicio "auxiliar", pero no son ellos los estructurantes de dicha tarea. Por eso nos preguntamos en qué medida la investigación acción participativa puede considerarse un método propio de la teología y cuáles son los alcances y límites que dicho método tiene.

Dividimos esta reflexión en tres partes. En primer lugar haremos una reseña sobre el método investigación acción participativa con el ánimo de explicitar sus aspectos más relevantes. En segundo lugar, nos preguntaremos por el quehacer teológico y su metodología propia; propondremos algunos fundamentos epistemológicos y metodológicos que podrían señalar cómo y en qué sentido puede articularse el método investigación acción participativa con la tarea teológica. Finalmente trazaremos algunas pistas para iluminar el uso de la investigación acción participativa en la reflexión teológica y, más precisamente, en las teologías contextuales.

\section{Características relevantes del método investigación acción participativa}

La investigación acción participativa se planteó en los siguientes términos:

[Como] una manera intencional de otorgar poder a la gente para que pueda asumir acciones eficaces hacia el mejoramiento de sus condiciones de vida. Lo novedoso no es que la gente se cuestione sobre sus condiciones y busque mejores medios de actuar para su bienestar y el de su comunidad, sino el hecho de llamar a este proceso investigación y de conducirlo como una actividad intelectual. ${ }^{6}$

\footnotetext{
${ }^{4}$ Parra, Textos, contextos y pretextos. Teología fundamental, 312-326.

${ }^{5} \mathrm{Al}$ final del escrito señalaremos aspectos de esta articulación.

${ }^{6}$ Park, “Qué es la investigación-acción participativa. Perspectivas teóricas y metodológicas”, 137.
} 
Podemos señalar tres periodos en su desarrollo:

(1) Surgimiento a partir de la psicología (1947) y la antropología acción (1945);

(2) desarrollos en la sociología, la antropología, la pedagogía a partir de los años setenta (Orlando Fals Borda ${ }^{7}$ ); (3) la internacionalización y la consolidación de la investigación acción participativa, en la década de los ochenta ${ }^{8}$.

En esta presentación no es nuestro objetivo detallar cada periodo sino detenernos en las características y principales desarrollos de la investigación acción participativa. Esta es una metodología que combina la teoría y la praxis y se plantea como "un proceso cíclico de acción-reflexión-acción"'. Se caracteriza porque rompe la diferencia entre el sujeto que investiga y los objetos que son investigados, proponiendo que los sujetos/objetos de la realidad que va a ser investigada se constituyan ellos mismos en sujetos/investigadores, y propicien así una relación horizontal entre todos los participantes.

Es verdad que los investigadores -que podrían llamarse académicos o especializados- son los que muchas veces se aproximan a una realidad y proponen a las personas de ese contexto realizar la investigación; pero el reto que tienen, a la hora de proponer la metodología investigación acción participativa, es el de ser capaces de actuar como "facilitadores", buscando empoderar a estas personas para que se conviertan en investigadoras de su propia realidad.

La investigación acción participativa parte del presupuesto de que las ciencias sociales no son neutrales sino que sus manifestaciones intelectuales repercuten en la vida material y simbólica de las sociedades. De la misma manera asume que el investigador también tiene sus propios presupuestos como sujeto social y desde allí realiza su investigación. Es decir, todo conocimiento tiene sus "pretextos" o "intencionalidades" y el "desde dónde" del investigador marca necesariamente su tarea.

La investigación acción participativa plantea cuestionamientos a los procedimientos metodológicos, operativos y técnicos de la investigación tradicional y ha sido un recurso conceptual y metodológico muy importante para la producción de conocimiento y transformación de la realidad en América Latina. Ahora bien, no es

\footnotetext{
${ }^{7}$ Considerado uno de los más destacados representantes y fundadores del método investigación acción participativa. Entre sus obras podemos señalar las siguientes: Una sociología sentipensante para América Latina (2009); Globalización y segunda República (2008); El socialismo raizal y la Gran Colombia bolivariana (2008).

${ }^{8}$ García Sánchez y Guerrero Barón, Núcleos de Educación Social, NES, Parte 2: "La fundamentación epistemológica del investigación acción participativa, IAP”), 101.

${ }^{9}$ Kirchner, "La investigación acción participativa", 2.
} 
una corriente metodológica de una única versión ${ }^{10}$. Se pueden identificar diferentes autores ${ }^{11}$ situados en sus contextos particulares que han producido investigación acción participativa con distintos acentos. Sin embargo, podemos destacar algunos rasgos comunes de estas diferentes versiones ${ }^{12}$ :

- El objetivo de la investigación acción participativa es generar cambios estructurales. Por tanto, no es solucionar problemas individuales sino tener un poder político, con el fin de llevar a cabo el cambio necesario.

- La investigación acción participativa produce conocimiento pero no a la manera tradicional, en la que unos transmiten conocimiento a los otros, sino que todos los participantes se involucran en la producción de conocimiento. Es, por supuesto, un conocimiento encaminado a la transformación.

La lógica de esta investigación es desde "dentro" y desde "abajo". Desde dentro de la comunidad estudiada y desde abajo porque participan todos, así no tengan estudios. La meta es que la comunidad sea gestora del proceso, aprendiendo de él y teniendo un control operativo (saber hacer), lógico (entender) y crítico (juzgar) de él. ${ }^{13}$

- El tipo de conocimiento que se espera conseguir no va tanto en la línea del conocimiento técnico (según la clasificación habermasiana) ${ }^{14}$-aunque no se excluye-, sino en la línea del conocimiento interactivo y social, que supone la comunicación entre los sujetos y la capacidad de tomar una postura crítica sobre la realidad a estudiar. - El conocimiento crítico acompañado por la acción es parte integral de la investigación acción participativa. Es decir, no solo provee de los conocimientos para entender las causas de los problemas sino capacita para actuar frente a ellos. Este método no termina con la adquisición de nuevos conocimientos sino con el compromiso de generar acciones transformadoras. Ahora bien, hay que evitar la división entre teoría y acción porque participar de la investigación ya es una forma de acción. - $\quad$ El punto de partida de este método es un problema que surge de los participantes y les afecta de tal manera que les interesa encontrar una solución. El investigador

${ }^{10}$ Leal, "La investigación acción participación, un aporte al conocimiento y a la transformación de Latinoamérica, en permanente movimiento", 14.

${ }^{11}$ Algunos autores significativos: de América Latina, Freire, Bosco, Cohen, Fals Borda, Mariño, Vio, Cendales, De Sousa; del Reino Unido, Elliott, O’Haniòn; de Australia: Mc Taggar, Gruñid. Ver a Leal, "La investigación acción participación, un aporte al conocimiento y a la transformación de Latinoamérica, en permanente movimiento", 21.

${ }^{12}$ Seguimos fundamentalmente los aportes de Park, "Qué es la investigación acción participativa. Perspectivas teóricas y metodológicas", 135-174.

${ }^{13}$ Kirchner, "La investigación acción participativa", 2.

${ }^{14}$ Ver a Habermas, Conocimiento e interés. 
académico -que debe actuar como facilitador- contribuye a la formulación del problema, pero no como observador sino como alguien implicado en esa realidad. Los demás pasos necesarios para llevar adelante la investigación -la definición de los métodos empleados, los procedimientos concretos, la forma de analizar los datos, etc.- han de ser discutidos por todos los participantes y asumidos por los mismos.

- En cuanto a los problemas que se quieren trabajar, se ha de tener en cuenta que son los participantes en la investigación los más capacitados para detectarlos y formularlos. Sin embargo, en algunas ocasiones, la misma complejidad del problema hace que los participantes no sepan verbalizarlo y que sea necesario emplear otras técnicas que saquen a la luz los sentimientos y vivencias que las palabras no logran expresar. Técnicas como los sociodramas, las fotografías, los dibujos, etc. son muy adecuadas para conseguir tal objetivo.

- $\quad$ En lo que se refiere a las técnicas o instrumentos para recoger los datos de la investigación, muchas veces se privilegian técnicas como la entrevista o el cuestionario porque estas permiten recoger datos y establecer diálogos en los que no solo se hace un intercambio de información sino también de sentimientos y valores. El diálogo es más que un método de investigación en cuanto facilita el encuentro de personas, y esto caracteriza la investigación acción participativa.

- $\quad$ La validez de este método es uno de los aspectos que más se ha discutido. En algunos ambientes académicos se duda de su confiabilidad, precisamente por los participantes y por la manera de proceder. Sin embargo, cada vez más se reconoce que en todo proceso investigativo juegan un papel determinante los intereses de los investigadores y ninguna investigación se libra de las tendencias marcadas por ellos.

En el caso de la investigación acción participativa, al reconocer esta condición humana de toda investigación, se descubren por el contrario dos ventajas para justificar la validez de la misma: (1) Los investigadores/participantes conocen experiencialmente de lo que hablan y por qué lo enfocan así; (2) las técnicas empleadas van más allá de la recolección de datos, porque se da el encuentro de personas en la interacción entre quien pregunta y quien responde.

La lógica es la de la participación igualitaria, que hace más visible y confiable las apuestas sociales y comunitarias. Se rompe también con el positivismo, que considera que el único conocimiento válido es el de las ciencias naturales y se afirma el conocimiento que viene de las ciencias humanas y sociales, donde la objetividad viene por la producción de relaciones de empatía y vinculación social y por la transformación a la que conducen los resultados obtenidos.

- En la misma línea del conocimiento que se produce, la investigación acción participativa recupera el conocimiento popular que permite que las habilidades 
prácticas de la gente -los sentimientos, las tradiciones y la sabiduría colectiva- jueguen un papel determinante en la historia más amplia del conocimiento y progreso humano.

Por tanto, la investigación acción participativa supone un nuevo enfoque epistemológico, metodológico, ético y político ${ }^{15}$ :

- Epistemológico, porque supone romper el binomio clásico positivista de separación entre el sujeto y el objeto de la investigación. En este caso, el sujeto es objeto de su propio conocimiento. Ello implica que la verdad se va logrando en la acción participativa comunitaria.

- Metodológico, porque supone que todos participan de manera procesual en el conocimiento estructural de la realidad, con el ánimo de transformarla. Se privilegian los métodos cualitativos, participativos y la construcción en colectivo de los resultados.

- Ético, porque se necesita esta actitud para trabajar con grupos humanos en la solución de sus problemas. En sí misma, la investigación acción participativa es una postura ética frente a las comunidades investigadas: es una actitud frente al conocimiento y frente a los actores participantes. Hay una condición de igualdad entre el investigador académico y todos los participantes, lo cual genera un contexto actitudinal y axiológico distinto frente a otros tipos de investigación.

- Político, porque implica la transformación de la realidad al generar un conocimiento que es una nueva actitud ante el poder.

La "experiencia vivida" cobra un papel fundamental en la construcción del conocimiento. Aquí no se trata de investigaciones "allá, fuera” sino de "existencias humanas" cargadas de sus problemáticas y de la urgente necesidad de transformarlas.

Junto a las características anotadas cabe señalar la categoría praxis como principio básico de desarrollo de la investigación acción participativa. El uso de esta categoría responde al contexto social de donde surge, que se expresa bien en las siguientes afirmaciones:

La "ciencia comprometida" surge como ruptura ideológica plegada al humanismo revolucionario de los años sesenta. Corresponde al acertijo y la escogencia entre "ciencia burguesa" y "ciencia proletaria" para ejercer una "praxis" en "toma de posiciones": de clase e ideología. A esta época corresponde también la emergencia

\footnotetext{
${ }^{15}$ García Sánchez y Guerrero Barón, Núcleos de Educación Social, NES, Parte 2: "La fundamentación epistemológica del investigación acción participativa -IAP"), 88-89; Kirchner, "La investigación acción participativa”, 3 .
} 
en América Latina de corrientes académico políticas en busca y en beneficio de "las masas" o "sectores populares", como la "pedagogía del oprimido" de Pablo Freire, la crítica a la escuela capitalista y a la neutralidad científica de Tomás Vasconi, la filosofía latinoamericana de Leopoldo Zea y la práctica neocristiana "en busca del arca" del cristianismo primitivo denominada "teología de la liberación". En ellas se inscribe una ruptura ideológica de carácter contestatario frente a la agresión y dominación imperial, en cuya gestión se enmarańa en distinciones que pretenden, sin lograrlo, realizar posibles "rupturas epistemológicas"... ${ }^{16}$

Muchos otros aspectos podrían señalarse sobre la investigación acción participativa. Sin embargo, los aquí anotados pueden ser suficientes para el objetivo primordial de la presente reflexión, que consiste en articular este método con el quehacer teológico.

\section{Algunos fundamentos epistemológicos y metodológicos: horizonte para asumir la investigación acción participativa como método de una investigación en teología}

No podríamos intentar articular un método de investigación como el de la investigación acción participativa con la teología si no partimos del presupuesto de que toda la realidad humana es lugar teológico, es decir, lugar donde podemos descubrir el acontecer de Dios.

El fundamento para la afirmación anterior lo encontramos en la constitución dogmática Dei Verbum:

...este plan de la revelación se realiza con hechos y palabras intrínsecamente conexos entre sí, de forma que las obras realizadas por Dios en la historia de la salvación manifiestan y confirman la doctrina y los hechos significados por las palabras, y las palabras, por su parte, proclaman las obras y esclarecen el misterio contenido en ellas. ( $D V 2)$

Esta manera de concebir la revelación en Vaticano II propició un nuevo horizonte en el quehacer teológico que, en América Latina, encontró gran resonancia en los movimientos sociales de esos años, como también en el caminar del Celam, especialmente en sus conferencias de Medellín y Puebla.

Sin embargo, esta realidad tan explícita posiblemente no ha sido tan asumida como pudiéramos creerlo, tal y como lo expresa Garavito:

${ }^{16}$ Torres, "Fals Borda y su obra. Reseña de Ciencia y compromiso", 88. 
...cincuenta años después de la apertura de Vaticano II, la teología posconciliar no ha profundizado suficientemente el sentido práxico del giro que proyecta la Dei Verbum. Este giro marca el tránsito del modelo dogmático al hermenéutico, lo que lleva a preguntarnos acerca del horizonte de interpretación más adecuado para la recepción teológica, en sus aspectos semántico-prácticos. ${ }^{17}$

La constitución pastoral Gaudium et spes va en la misma línea de la Dei Verbum, al reconocer la "autonomía de las realidades terrestres" (GS36). Esta afirmación supone tomarse en serio la actividad humana en el mundo (GS 33-36). La Iglesia, en este documento, se pregunta: ¿Cuál es el sentido y valor de la actividad humana? ¿Qué uso se ha de hacer de todas estas cosas? ¿A qué fin conspira el esfuerzo de individuos y sociedades? Al responder, reconoce que al ser ella guardiana de la Palabra de Dios, sin tener por ello respuesta a todas las cuestiones, ha de unir la luz de la revelación a la inteligencia de todos para iluminar toda actividad humana. Más aún afirma que una cosa es cierta para los creyentes:

...la actividad humana individual y colectiva o el conjunto ingente de esfuerzos realizados por el hombre a lo largo de los siglos, para lograr mejores condiciones de vida, considerado en sí mismo, responde a la voluntad de Dios [...] y con razón puede pensar que con su trabajo desarrollan la obra del Creador, sirve al bien de sus hermanos y contribuyen de modo personal, a que se cumplan los designios de Dios en la historia" (GS 33-34).

\section{La teología de la liberación: nueva manera de hacer teología}

El reconocimiento de la "revelación de Dios en la historia” y de su acontecer, no en dos planos de realidad (sobrenatural y natural) sino en el único plano natural donde lo trascendente se revela ${ }^{18}$, contribuyó a formular una teología en términos de praxis, historia, acción. Es así como la conocida “teología de la liberación” destacó la primacía de la praxis como punto de partida de dicha reflexión teológica. En el pensamiento de Gustavo Gutiérrez la praxis sería "el acto primero" mientras que la teoría teológica "el acto segundo"19.

\footnotetext{
${ }^{17}$ Garavito, "La revelación y la actividad humana: recepción teológica de la constitución Dei Verbum en clave hermenéutica de la apropiación”, 1.

18 "Esta compatibilidad de la revelación y la actividad humana confirma la unicidad de la historia y constituye el escenario predilecto en que Dios lleva a cabo la historia de la salvación" (Garavito, "La revelación y la actividad humana”, 14).

${ }^{19}$ Gutiérrez, La revelación y la actividad humana: Recepción teológica de la constitución Dei Verbum en clave hermenéutica de la apropiación, 28.
} 
Esta primacía de la praxis estaba sustentada por la filosofía marxista y por la filosofía de la acción de Maurice Blondel ${ }^{20}$. Es así como la propuesta metodológica de esta teología propuso las distintas mediaciones, entre las cuales la mediación socioanalítica constituye el primer paso del método, la mediación hermenéutica el segundo, y la dialéctica teoría-praxis, el tercero. ${ }^{21}$

La mediación socioanalítica, aunque se considera un momento preteológico, es parte del método porque se ocupa del objeto a investigar. Esta mediación aporta "el dato de la ciencia” para pasar, en un segundo momento, a la mediación hermenéutica. De alguna manera, dicho esfuerzo supone asumir -con todas las consecuencias- la autonomía de las realidades terrestres, y por eso se necesita de las ciencias sociales para captar el dato de la realidad. Este momento conlleva, entonces, un trabajo interdisciplinario, con las dificultades que esto trae. Por eso, los teólogos de la liberación alertaban de los obstáculos para llevar a cabo esa articulación.

O se puede caer en el empirismo (conocer la realidad sin mediación) o en el purismo metodológico (la teología no acepta la contribución de otras ciencias) o en el teologismo (la teología substituye la mediación socioanalítica), o en la mezcla semántica (se mezcla el discurso social en la teología), o en el bilingüismo (se yuxtaponen los dos lenguajes). La verdadera relación de constitución entre la teología y las ciencias sociales supone apropiarse del dato con los métodos señalados por las ciencias de lo social y en un segundo momento realizar la mediación hermenéutica.

Existen diferentes tipos de análisis social, entre los cuales la metodología teológica ha de escoger para llevar a cabo el primer momento del método. Entre estos tipos de análisis social pueden señalarse: el estructural, el funcionalista, el analítico crítico, etc. La teología de la liberación privilegió el último, porque supera los otros análisis adentrándose en las causas de los fenómenos sociales, en la interrelación e interacción de los elementos varios del sistema y de sus puntos de conflicto.

Este análisis se pregunta cuáles son las causas del desequilibrio y la consiguiente insatisfacción en el ordenamiento social vigente y cómo y por qué reformarlo o sustituirlo plenamente. Sin embargo, el análisis social ha de pasar al plano teológico para no quedarse solo con los resultados de la sociología, y por eso se pregunta cuáles son los imperativos de reforma o de sustitución del ordenamiento social vigente a la luz de la revelación salvadora de Dios y en obediencia a la fe teologal y eclesial. ${ }^{22}$

\footnotetext{
${ }^{20}$ González, Teología de la praxis evangélica: ensayo de una teología fundamental, 75-76, citado por Parra, "De camino a la teología de la acción", 150.

${ }^{21}$ Ver a Boff, Teología de lo político: sus mediaciones.

${ }^{22}$ Parra, Textos, contextos, pretextos, 318-319.
} 
La pregunta que puede surgirnos es por el uso del método investigación acción participativa en la teología de la liberación. La cercanía del sacerdote colombiano Camilo Torres con Orlando Fals Borda hace suponer que en este contexto tuvo que existir cierta articulación. Así lo expresan algunos autores:

...los estudiosos de su obra [de Fals Borda] coinciden en la articulación que se dio entre su trabajo comunitario y la expansión de la teología de la liberación y su permanente contacto con los seguidores de estas tendencias así como con su similitud y contemporaneidad con el pensamiento de Paulo Freire y de otros socialistas latinoamericanos. ${ }^{23}$

Cabría entonces pensar que la investigación acción participativa podría proponerse como método social para realizar el primer momento del método de la teología de la liberación, la mediación socioanalítica. Sin embargo, es necesario anotar las continuas insistencias que los teólogos de la liberación han hecho sobre la primacía de la fe y de la experiencia de Dios en la captación de la realidad, para que la teología sea en realidad teología y no cualquier otro discurso que trate de Dios y de la realidad, pero no necesariamente desde la óptica teológica. En este sentido podemos referirnos a dos propuestas que de alguna manera quieren completar la propuesta metodológica de las tres mediaciones para que el proceso metodológico sea realmente teológico.

En primer lugar nos referimos a Clodovis Boff, quien -en su obra sobre el método teológico, Teoría do método teológico ${ }^{24}$ - estructura la teoría sobre el método teológico a partir de tres aspectos, a saber:

- Los fundamentos en los cuales desarrolla la fe como palabra, como experiencia y como práctica, fuente primera del quehacer teológico.

- Los procesos que se dan en la tarea teológica y se refieren a: (1) Momento positivo: la Sagrada Escritura, la tradición y el dogma; (2) Momento constructivo: la tarea de reflexión o especulación teológica. Y (3) la analogía como lenguaje propio de la teología.

- Las articulaciones que ha de tener la teología con la filosofía y las demás ciencias, con el magisterio y con el pluralismo religioso.

\footnotetext{
${ }^{23}$ García Sánchez y Guerrero Barón, Núcleos de Educación Social, NES, Parte 2: "La fundamentación epistemológica del investigación acción participativa -IAP”), 110.

${ }^{24}$ Recordemos que este mismo autor, en su obra Teología de lo político, sistematizó las tres mediaciones de la teología de la liberación; y en esta obra posterior, pretende ofrecer un horizonte más completo de la misma.
} 
Al dejar sentadas estas bases, Clodovis Boff considera que se salva la primacía de la fe y se evita el peligro de una sociologización de la teología.

En segundo lugar nos referimos a la presentación de Alberto Parra, S. J. ${ }^{25}$ sobre el proceso metodológico de la teología de la liberación a partir de la definición propuesta por Gutiérrez, "reflexión crítica sobre la praxis histórica a la luz de la fe", que permiten mantener la tensión entre el polo fundante de la fe y el compromiso con la realidad y el Dios que se revela en la historia. Así, el acto primero -la praxis histórica- tiene que ver con la pregunta por el bien humano comprendido y actuado a la luz de Dios y su plan de salvación. Por eso, la praxis ética de liberación es el punto de partida del método en cuanto se convierte en criterio de verificación de la experiencia de Dios de la que el teólogo o la teóloga no puede prescindir porque el imperativo evangélico de "ve y haz tú lo mismo" (Lc 10,37) o de "quien lo hizo con uno de estos más pequeños, conmigo lo hizo" (Mt 25,40) es la religión que Dios quiere, el sacrificio que acepta, la auténtica verdad revelada (Is 8, 6-8).

Por su parte, el acto segundo -la reflexión crítica- se refiere al análisis del contexto de situación. Esta no puede ser una lectura ingenua o acrítica, sino ayudada por el instrumental analítico dispuesto por las ciencias naturales, hermenéuticas y sociales, que siempre cuenta con el sujeto que realiza dicha ciencia, un sujeto que -ayudado por los análisis científicos- quiere captar esa realidad en el horizonte de la revelación y en obediencia a la fe, desde y para una praxis de liberación.

La posibilidad de esta lectura es consecuencia del Dios que se revela en la historia. Por eso se necesita la labor teológica capaz de discernir los métodos adecuados para tal lectura -sin olvidar que estos son medios y no fin- y la libertad evangélica para liberarse de ideologías en boga que pueden traicionar una captación auténtica del acontecer de Dios en la historia ${ }^{26}$.

Finalmente, el acto tercero - a la luz de la fe-constituye tanto la praxis liberadora como la reflexión crítica en formalidad teológica:

Una reflexión crítica sobre la praxis histórica de los hombres será teológica, en la medida en que ausculte en esta praxis la presencia de la fe cristiana. Es esto lo que distingue la teología de las demás posibilidades de reflexionar críticamente

\footnotetext{
${ }^{25}$ Parra, Textos, contextos, pretextos, 312-326.

${ }^{26}$ La relación con las otras ciencias ha de mantenerse, respetando su autonomía, pero siempre desde el horizonte de la fe que hace posible discernir entre lo positivo que se compatibiliza con la fe, y rechazando lo negativo que se contrapone a la fe revelada. Ver a Boff, Teoría do método teológico, 384.
} 
sobre la praxis. Cuando esta referencia a la pregunta sobre el sentido de la fe de esta praxis estuviere enteramente descartada, no hay teología. ${ }^{27}$

En este sentido, mediaciones históricas tales como la Sagrada Escritura y la tradición, el magisterio y la vida de fe, y la vida de la Iglesia, son el texto hermenéutico para interpretar el contexto de situación y animar el pretexto de liberación. No hay que olvidar que estas mismas mediaciones están mediadas históricamente y por eso el criterio de fidelidad al núcleo central de la fe siempre ha de liberarlas de interpretaciones acomodadas a los intereses de algunos que no se corresponden con el interés de Dios. Además de estas mediaciones históricas está la mediación del acontecer presente que sostiene la ininterrumpida locución de Dios en la historia. Por tanto, toda la historia es lugar teológeno (generador de la teología) en su aspecto de materialidad previa a la formalidad teológica.

\section{Las teologías contextuales: partir de la experiencia de vida ${ }^{28}$}

En el mismo sentido de la teología de la liberación, las teologías contextuales parten de la praxis histórica de liberación pero haciendo énfasis en realidades particulares y en sujetos concretos que, desde su experiencia de vida, la teologizan y buscan iluminarla desde los datos de la fe, para transformar esa situación que no corresponde al querer divino. Brevemente podemos referirnos a algunas de estas teologías.

En el caso de la teología feminista, su punto de partida es la experiencia de opresión que sufren las mujeres y que aun cuando viene condicionada por el estrato socioeconómico, la etnia, la religión, etc., es una opresión que sufren casi todas las mujeres de casi todas las partes del mundo. Esta teología denuncia el sexismo, la mentalidad androcéntrica y el patriarcado que ha configurado a las sociedades y a las iglesias. Al mismo tiempo anuncia la posibilidad de nuevas configuraciones genéricas que liberen de los estereotipos patriarcales que han hecho de los varones y mujeres seres determinados para un tipo de funciones, impidiendo una realización más integral y plena.

La teología afro y afro-americana parte de la experiencia del racismo vivido en las diferentes latitudes, bien como Apartheid en Sudáfrica, como segregación racial en Estados Unidos y como opresión y esclavitud en América, y busca la liberación

\footnotetext{
${ }^{27}$ Assmann, Teología desde la praxis de liberación. Ensayo teológico desde América dependiente, 49-50, citado por Parra, Textos, contextos, pretextos, 322-323.

${ }^{28}$ Un estudio más detallado de estas y otras teologías contextuales en Tamayo-Acosta, Nuevo paradigma teológico.
} 
de esas situaciones y la restitución de la dignidad negada. Al mismo tiempo anuncia la superación de la "anemia blanca" que azota el cristianismo católico y el etnocentrismo que ha impedido la vida digna de tantos seres humanos. Reconoce los valores culturales de comunidad y solidaridad que estos pueblos han cultivado y que hoy se erigen como posibilidad de restitución de comunidades rotas y divididas.

La teología amerindia parte de la experiencia de avasallamiento de los pueblos originarios por parte de los colonizadores, que violenta sus creencias, sus tradiciones, su integridad personal e impone sus visiones de mundo, cultura y religión. Anuncia la restitución de sus tradiciones originales como ricas de significado y constitutivas de las culturas amerindias que, lejos de rechazarse, tendrían que integrarse y promoverse. Apuntan al reconocimiento de lo autóctono, con su potencial liberador, para recuperar lo que nunca debió ser negado.

La teología ecológica y holística denuncia la violencia con la madre Tierra y el abuso depredador del cosmos y la casa común que habitamos. La mentalidad tecnológica y productivista, que solo ve ganancia y lucro en todo lo que toca, abusó de esta casa común, muchas veces en nombre de la centralidad antropológica -mal entendida- promovida por la fe cristiana, y contribuye a la situación de peligro ecológico en el que hoy nos encontramos. El anuncio de una ecología integral se propone hoy como urgente y desafiante para quienes comparten este mundo habitable, si se quiere preservar para muchas más generaciones.

La teología intercultural y la teología del pluralismo religioso parten también de la constatación de la pluralidad cultural y religiosa que los seres humanos viven y que, en lugar de empobrecerlos, los enriquece en la medida en que se descubra y se practique la mutua colaboración, el respeto sincero y la apertura adecuada para crecer y transformarse desde su propia matriz.

Del mismo modo podríamos hacer referencia a otras teologías, como la teología queer, la teología poscolonial y otras muchas teologías contextuales o paradigmas o nuevos enfoques que muestran la riqueza de quehacer teológico y su diversidad fecunda cuando parte de la autonomía de las realidades terrestres -como afirma la Gaudium et spes 36- sabe descubrir en ellas la voz de Dios y se propone interpretarla con los medios adecuados para ello. Toda la realidad -como ya hemos afirmado- es lugar de revelación, y la teología tiene la tarea de desvelar esa palabra y contribuir a su eficacia en la transformación de la realidad.

La articulación entre estas teologías contextuales y el método investigación acción participativa es clara en el punto de partida de las mismas. La experiencia de los sujetos de estas teologías no es una reflexión teológica elaborada en los escritorios. Son los mismos participantes en las investigaciones quienes por medio del método 
investigación acción participativa pueden ofrecer ese lugar teológico -sus propias experiencias- para descubrir en este el querer de Dios y la iluminación de esa realidad desde su voluntad salvífica.

\section{La teología de la acción: ampliación del concepto de praxis y actualización del revelarse de Dios en la historia}

La centralidad de la praxis en la teología de la liberación ha sido notoria, como se expresó en el apartado anterior; pero hoy nos encontramos con nuevas reflexiones que buscan ampliar este concepto, redefinirlo, reubicarlo, devolverle su sentido más integral. Nos referimos a la llamada "teología de la acción" que en sus desarrollos actuales puede aportar nuevas luces al caminar teológico y al interés de nuestra reflexión: articular el método investigación acción participativa con el quehacer teológico.

De acuerdo con los aportes de Antonio González, se propone hoy hablar de la "teología de la acción" más que de una teología pastoral o teología práctica, porque este término nos remite a una comprensión de la praxis en su acepción griega, en la cual la teoría (qeoria) no es ajena a la praxis (praxiô) y excluye un entender la praxis en sentido de poiesis (poibsij), es decir, como hacer práctico y producir técnico ${ }^{29}$. En otras palabras, hoy en día,

...se torna ontológica y éticamente indispensable dar un paso atrás, que es sustantivo paso hacia adelante, en orden a recuperar el primado del acto humano, de la acción humana, de la actuación, de la actividad y luego de la praxis misma, con que se reconstituya el tejido del ser y del pensar, la intencionalidad y la racionalidad previa a las objetivaciones funcionales de nuestro ser..$^{30}$

Hablar por tanto de acción humana supone reconstituir la ruptura epistemológica que se dio con el materialismo histórico entre el pensar y el actuar. En el planteamiento que venimos haciendo, el actuar tiene en sí mismo una instancia teórica que luego se realiza en diferentes determinaciones. En la versión habermasiana supone un conocimiento regido por tres intereses ${ }^{31}$, y en la versión lonerganiana, el dinamismo de la conciencia intencional, que en sus cuatro niveles experimenta, entiende, juzga y decide, como niveles del conocimiento que llevan a la acción ${ }^{32}$. Es

\footnotetext{
${ }^{29}$ González, Teología de la praxis evangélica, 76.

${ }^{30}$ Parra, "De camino a la teología de la acción”, 151.

${ }^{31} \mathrm{El}$ interés adaptativo en las disciplinas naturales, el interés comunicativo en las disciplinas humanas y el interés emancipador en las ciencias sociales. Ver a Habermas, Conocimiento e interés, 159-181.

${ }^{32}$ Lonergan, Método en teología, 16-17.
} 
decir, la acción humana, antes de ser "técnica, práctica y aplicación", es acción humana previa a esas determinaciones ${ }^{33}$.

No menos importante es el papel que juega el lenguaje y que en los nuevos análisis se expresa como "el hacer del decir en los análisis del lenguaje". ${ }^{44}$ Podría aquí invocarse a Lonergan, quien al hablar de las funciones de la significación se remite a estas cuatro: comunicativa, constitutiva, cognoscitiva y eficiente.

El lenguaje no son simplemente signos, palabras, sonidos, sino tiene una función cognoscitiva porque nos saca del mundo de la inmediatez y nos introduce en el mundo mediado por la significación. Es el mundo que abarca el pasado, el presente y el futuro, y no solo lo conocido sino lo que aún no hemos conocido, porque no se refiere a la sola experiencia sino que se arraiga en la estructura dinámica del conocimiento, que supone también el comprender y el juicio.

El lenguaje tiene una función eficiente porque todo lo que imaginamos, planeamos, organizamos consiste en actos de significación que nos permiten encauzar con más eficiencia la finalidad que pretendemos.

El lenguaje tiene una función constitutiva porque las significaciones forman la tradición cultural y religiosa que constituye a los individuos y los pueblos.

Finalmente, el lenguaje tiene una función comunicativa y es la posibilidad de que lo que un individuo significa se comunique a otro de manera intersubjetiva, artística, simbólica, lingüística y personificada ${ }^{35}$.

Expresado en otros términos, el lenguaje es también dabar, que en la Sagrada Escritura no solo significa sino que produce lo significado, en una lógica locutiva y perlocutiva en la que la Palabra se hace acción y se realiza como acción transformante y transformadora ${ }^{36}$ :

Porque como descienden de los cielos la lluvia y la nieve, y no vuelven allá sino que riegan la tierra, haciéndola producir y germinar, dando semilla al sembrador y pan al que come, así será mi palabra que sale de mi boca, no volverá a mí vacía sin haber realizado lo que deseo, y logrado el propósito para el cual la envié. (Is 55,10-11).

El decir del hacer que está en la base del surgir anamnético de los textos de tradición es inseparable del hacer del decir como referencia cierta del discurso, en tanto que el decir es hacer, pone en acción las reservas de la fe como obediencia histórica. Es así, entonces, como la teología de la acción desata el

\footnotetext{
${ }^{33}$ Parra, "De camino a la teología de la acción", 152.

${ }^{34}$ Ibíd., 154.

${ }^{35}$ Lonergan, Método en teología, 79-82.

${ }^{36}$ Parra, "De camino a la teología de la acción”, 165.
} 
movimiento, la actualidad y la situación de las reservas espléndidas - pero hoy insufriblemente estáticas- de la función bíblica y de la función sistemática de la disciplina teológica. ${ }^{37}$

En consonancia con la revelación de Dios en la historia podemos afirmar que la acción humana no es un simple receptáculo de aplicación de las doctrinas reveladas sino que ella misma es lugar teológico donde acontece la revelación:

La teología de la acción encuentra así, no solo su objeto material, sino formal, constituidos por la actividad humana en el mundo, en cuanto es actividad categorial e inmanente puede ser y es de hecho modo de revelación actuante y operante del Dios radicalmente trascendente. ${ }^{38}$

La teología de la acción indica, pues, que la materia prima sobre la que se instituye la reflexión teológica es, precisamente, el acto, la acción, la actuación, la actividad, la praxis; y que el teólogo de la acción es quien instituye su reflexión teológica a partir del obrar humano en la práctica cultural, económica, política, social, eclesial, doméstica y laboral, ya sea que se trate del hacer, del realizar o de teorizar la práctica humana para dinamizar el proceso integral de transformación presente y trascendente a la luz del proyecto de Dios y de su plan de gracia. ${ }^{39}$

El método propio de la teología de la acción consiste en un partir de la acción humana que corresponde al "ver", acción que es interpretada, asumida y relacionada en términos teológicos correspondiendo al "juzgar", para proponer procesos de transformación de esa acción humana percibida previamente en términos del hacer o del "actuar".

Una teología de la acción cumple la finalidad de ofrecer a las teologías de la praxis una noción más completa de praxis, evitándole caer en ingenuos practicismos e inmediatismos sociales y políticos a falta de una comprensión adecuada de las raíces ontológicas del acto, de la acción, de la actividad. Además, esta visión más amplia de teología de la acción permite que los sujetos/destinatarios no sean solo los miembros de la Iglesia en una teología pastoral o los pobres en una teología de la liberación. Más importante aún es ampliar el campo de la teología de la acción no solo al hacer sino incluyendo el pensar y el teorizar en el acto del quehacer teológico en esta especialización ${ }^{40}$.

\footnotetext{
${ }^{37}$ Ibíd., 166.

${ }^{38}$ Ibíd., 160.

${ }^{39}$ Ibíd., 160-161.

${ }^{40}$ Ibíd., 166-167.
} 


\section{Hacia una reflexión teológica a partir de la investigación acción participativa: posibilidades y límites}

En este apartado propongo abrir el diálogo y la construcción colectiva sobre el tema que estamos considerando: las posibilidades y límites de la investigación acción participativa en la tarea teológica.

Parto afirmando que en el recorrido hecho hasta ahora pudimos mostrar que las teologías de la praxis o -al ahondar en este concepto- las teologías de la acción dan cabida al método de la investigación acción participativa para realizar la reflexión teológica. Este es un método adecuado para captar la realidad como ella es, desde su autonomía propia, con sus preguntas y desafíos. Añade aspectos importantes que pueden enriquecer esa captación, tales como partir de los mismos sujetos implicados en determinada problemática, la construcción colectiva que supone y la diversidad de lenguajes que conlleva: no solo la lógica del discurso racional sino también la sabiduría del discurso popular, la significación intersubjetiva, la artística, simbólica, experiencial. En otras palabras, propone un conocimiento que no es unidireccional, sino participativo y democrático, y unas nuevas maneras de hablar, de decir, de significar.

Una tarea teológica que no parta de la vida y no pretenda transformarla se queda en la esterilidad de las especulaciones teóricas, sin ninguna conexión con la realidad y/o en la acumulación de reflexiones teológicas que no responden al momento actual. Por eso, al favorecer un método inductivo y trasformador -como la investigación acción participativa- se garantiza, en gran parte, un discurso teológico que asuma tanto las especializaciones de fundamentos, doctrinas y sistemáticas, como las "comunicaciones" ${ }^{41}$ que conlleva las cuatro funciones de la significación antes descritas y que podemos expresar así:

Comunicar el mensaje cristiano es llevar a otro individuo a compartir una significación cognoscitiva, constitutiva y eficiente, que uno ha hecho ya propia. Por consiguiente, todos los que vayan a comunicar la significación cognoscitiva del mensaje cristiano, antes que nada, deben conocer [...]. Quienes van a comunicar la significación constitutiva del mensaje cristiano deben ante todo vivirla. Porque quien no vive ese mensaje no puede poseer su significación constitutiva, y no puede llevar a nadie para compartir lo que él mismo no posee. Finalmente, los que comunica la significación eficiente del mensaje cristiano, deben ponerla en práctica. En efecto, las acciones hablan más que las palabras;

\footnotetext{
${ }^{41}$ Para un estudio detallado de las especializaciones del método teológico (investigación, interpretación, historia, dialéctica, fundamentos, doctrinas, sistemáticas y comunicaciones), ver a Lonergan, Método en teología.
} 
y predicar lo que no se practica hace pensar en un bronce que resuena, hoy en una campana que tañe. ${ }^{42}$

La investigación acción participativa dirige la tarea teológica a la realización del círculo de acción-reflexión-acción, ya que su pretensión es transformar la realidad, y en esto coincide con las teologías de la praxis que se validan en esa coherencia con los cambios que producen.

El desafío que queda pendiente al privilegiar la investigación acción participativa para la realización de las investigaciones teológicas es no perder de vista que este método nos permite considerar el objeto material de la reflexión teológica, pero hemos de interpretarlo desde el aspecto formal, propiamente teológico, para cumplir con los objetivos propuestos.

La dinámica del círculo hermenéutico donde la fe es el horizonte de cualquier acercamiento a la realidad y el dinamismo que acompańa todo el proceso -a su vez que es punto de llegada que se valida, justamente, con el compromiso liberador y transformador-, nos permite realizar un ejercicio teológico que articula los diversos momentos del método, muestra cómo el acercamiento a la realidad se hace desde el horizonte de fe que mueve nuestras investigaciones para interpretarla, no desde un subjetivismo o relativismo -sea este personal o comunitario-, sino acudiendo a las fuentes irrenunciables del quehacer teológico -Sagrada Escritura y tradición- junto a todo el acervo eclesial, teológico e interdisciplinar que aporta luz sobre las realidades consideradas.

Es decir, la investigación acción participativa ha de articularse con los métodos hermenéuticos propios del quehacer teológico, para lograr una visión desde la fe del problema considerado. De no hacerlo, se estaría limitando dicha tarea y sus resultados no podrían inscribirse en la investigación teológica.

Los temas que traemos entre manos, llámense sexualidad, salud reproductiva, derechos humanos, corporeidad, espiritualidad, educación cristiana, etc., necesitan ser iluminados con los "textos de tradición” ${ }^{43}$, de manera que las propuestas liberadoras y transformadoras que se infieran puedan develar la voluntad salvífica de Dios sobre la humanidad y sobre toda la creación.

Si toda la realidad es susceptible de ser teologizada, la visión de fe en su desdoblamiento teológico tiene un aporte que hacer al devenir humano, en el amplio concierto de las ciencias, y esta ha de ser la apuesta en las investigaciones teológicas que pretendemos realizar.

\footnotetext{
${ }^{42}$ Ibíd., 347-348.

${ }^{43}$ Parra, Textos, contextos, pretextos, 323-326.
} 


\section{Bibliografía}

Assmann, Hugo. Teología desde la praxis de liberación. Ensayo teológico desde América dependiente. Salamanca: Sígueme, 1976.

Boff, Clodovis. Teología de lo politico: sus mediaciones. Salamanca: Sígueme, 1980. . Teoría do método teológico. Petrópolis: Vozes, 1998.

Concilio Vaticano II. "Constitución pastoral Gaudium et spes (1965)". Vatican, http:// www.vatican.va/archive/hist_councils/ii_vatican_council/documents/vatii_const_19651207_gaudium-et-spes_sp.html\# (consultado el 12 de octubre de 2015).

Fals Borda, Orlando. El socialismo raizaly la Gran Colombia bolivariana. Investigación acción participativa. Caracas: Promoción Social, 2008.

- "Globalización y segunda República". En Cuadernos del pensamiento crítico latinoamericano. Buenos Aires, Clacso, 2008. Disponible en: http:// bibliotecavirtual.clacso.org.ar/ar/libros/secret/cuadernos/fals/fals.pdf (consultado el 30 de agosto de 2016).

. Una sociología sentipensante para América Latina. Buenos Aires: Clacso, 2009.

Garavito Villareal, Daniel de Jesús. "La revelación y la actividad humana: recepción teológica de la constitución Dei Verbum en clave hermenéutica de la apropiación”. Ponencia para la sustentación de su tesis de Doctorado, 16 de julio de 2014 (sin publicar).

García Sánchez, Bárbara Yadira y Javier Guerrero Barón. Núcleos de Educación Social, NES. Bogotá: Universidad Distrital Francisco José de Caldas, 2012. Disponible en: http://ascun.org.co/media/attachments/nucleos_de_educacion_ social_nes.pdf (consultado el 3 de marzo de 2015).

González, Antonio. Teología de la praxis evangélica: ensayo de una teología fundamental. Santander: Sal Terrae, 1999.

Gutiérrez, Gustavo. La teología de la liberación. Perspectivas. Lima: CEP, 1971.

Habermas, Jürgen. Conocimiento e interés. Madrid: Taurus, 1982.

Kirchner, Alicia. "La investigación acción participativa”. Foro Latinoamérica, http://forolatinoamerica.desarrollosocial.gov.ar/galardon/docs/Investigaci\%C3\%B3n\%20Acci\%C3\%B3n\%20Participativa.pdf (consultado el 3 de marzo de 2015). 
Leal Eduardo. "La investigación acción participación, un aporte conocimiento y a la transformación de Latinoamérica, en permanente movimiento”. Revista de investigación 67, Vol. 33 (2009): 14-34. Disponible en: Scielo, http://www2. scielo.org.ve/pdf/ri/v33n67/art02.pdf (consultado el 3 de marzo de 2015).

Lonergan, Bernard. Método en teología. Salamanca: Sígueme, 1994.

Park, Peter. "Qué es la investigación acción participativa. Perspectivas teóricas y metodológicas”. En La investigación acción participativa. Inicios y desarrollos, editado por María Cristiana Salazar, 135-174. Bogotá: Magisterio, 2011.

Parra, Alberto. "De camino a la teología de la acción”. Theologica Xaveriana 175 (2013): 143-171.

. "Interacción del saber científico en perspectiva teológica". Theológica Xaveriana 112 (1994): 401-425.

. Textos, contextos y pretextos. Teología fundamental. Bogotá: Pontificia Universidad Javeriana, Facultad de Teología, 2003.

Tamayo-Acosta, Juan José, Nuevo paradima teológico. Madrid: Trotta, 2003.

Torres, William. "Fals Borda y su obra. Reseña de Ciencia y compromiso". Boletín cultural y bibliográfico Vol. XXIV, 12 (1987): 88-89. Disponible en: Boletín cultural y bibliográfico del Banco de la República, http://publicaciones.banrepcultural.org/ index.php/boletin_cultural/issue/view/96 (consultado el 3 de marzo de 2015).

Vélez Caro, Olga Consuelo. El método teológico. Fundamentos, especializaciones, enfoques. Bogotá: Pontificia Universidad Javeriana, Facultad de Teología, 2008. 